2017-04-01

\title{
The Nicotine Content of a Sample of E-cigarette Liquid Manufactured in the United States
}

Barrett H. Raymond

Brigham Young University

Follow this and additional works at: https://scholarsarchive.byu.edu/etd

Part of the Nursing Commons

\section{BYU ScholarsArchive Citation}

Raymond, Barrett H., "The Nicotine Content of a Sample of E-cigarette Liquid Manufactured in the United States" (2017). All Theses and Dissertations. 6726.

https://scholarsarchive.byu.edu/etd/6726

This Thesis is brought to you for free and open access by BYU ScholarsArchive. It has been accepted for inclusion in All Theses and Dissertations by an authorized administrator of BYU ScholarsArchive. For more information, please contact scholarsarchive@byu.edu, ellen_amatangelo@byu.edu. 
The Nicotine Content of a Sample of E-Cigarette

Liquid Manufactured in the United States

Barrett H. Raymond

A thesis submitted to the faculty of

Brigham Young University

in partial fulfillment of the requirements for the degree of

Master of Science

Katreena Collette Merrill, Chair
Roger G. Harrison
Sabrina Jarvis
Ryan Jay Rasmussen

College of Nursing

Brigham Young University

Copyright (C) 2017 Barrett H. Raymond

All Rights Reserved 


\author{
ABSTRACT \\ The Nicotine Content of a Sample of E-Cigarette \\ Liquid Manufactured in the United States \\ Barrett H. Raymond \\ College of Nursing, BYU \\ Master of Science
}

Background: Use of electronic cigarettes (EC) has dramatically increased in the United States since 2010 with a forecasted growth of $37 \%$ between 2014 and 2019 . There is little research on e-liquid nicotine concentration from domestic manufacturers. However, limited research outside of the U.S. found wide inconsistencies between the labeled concentration of nicotine in e-liquids and the actual nicotine concentration.

Methods: The seven most popular online manufacturers or distributors were identified. E-liquid samples of the five most popular flavors from each manufacturer were purchased in nicotine concentrations of $0 \mathrm{mg} / \mathrm{ml}$ and $18 \mathrm{mg} / \mathrm{ml}$. Of the samples purchased $(\mathrm{n}=70)$, all were labeled as produced in the United States of America (USA). The researchers anonymized the samples before sending them to an independent university lab for testing.

Results: The 35 e-liquid samples labeled $18 \mathrm{mg} / \mathrm{ml}$ nicotine measured between 11.6 and 27.4 $\mathrm{mg} / \mathrm{ml}(\mathrm{M}=18.7 \mathrm{SD}=3.3)$ nicotine. The labeled $18 \mathrm{mg} / \mathrm{ml} \mathrm{samples} \mathrm{measured} \mathrm{as} \mathrm{little} \mathrm{as} 35 \%$ less nicotine and as much as 52\% greater nicotine. In the 35 samples labeled $0 \mathrm{mg} / \mathrm{ml}$, nicotine was detected $(>0.01 \mathrm{mg} / \mathrm{ml})$ in $91.4 \%$ of the samples (Range $=0$ to $23.9 \mathrm{mg} / \mathrm{ml} ; \mathrm{M}=2.9 ; \mathrm{SD}=7.2$ ). Six samples from two manufacturers labeled as $0 \mathrm{mg} / \mathrm{ml}$ were found to contain nicotine in amounts ranging from $5.7 \mathrm{mg} / \mathrm{ml}$ to $23.9 \mathrm{mg} / \mathrm{ml}$.

Conclusion: This study demonstrates the nicotine labeling inaccuracies present in current eliquid solutions produced in the U.S. Incorrect labeling poses a significant risk to consumers and supports the recent regulation changes enacted by the FDA. Additional routine testing of nicotine concentrations should be conducted to evaluate the effectiveness of the regulations on future eliquid production.

Keywords: nicotine, e-cigarette, addiction, e-juice, smoking, vaping, e-liquid 


\section{TABLE OF CONTENTS}

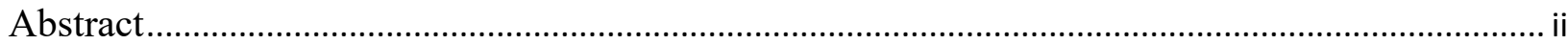

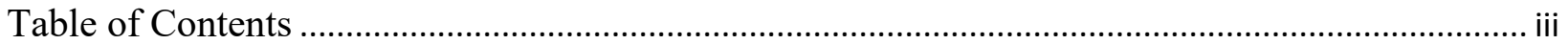

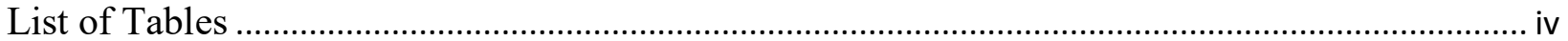

The Nicotine Content of a Sample of E-cigarette Liquid

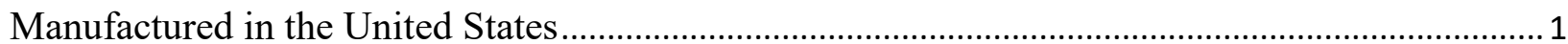

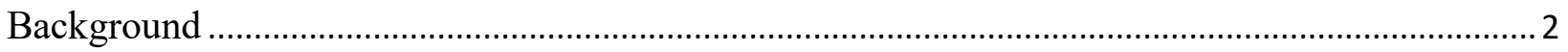

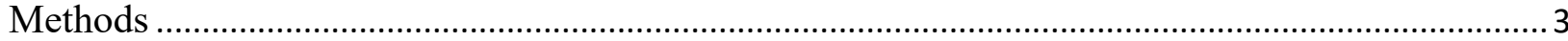

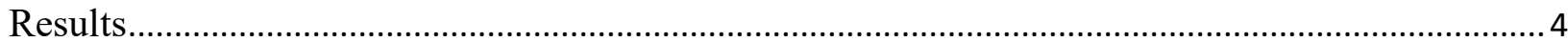

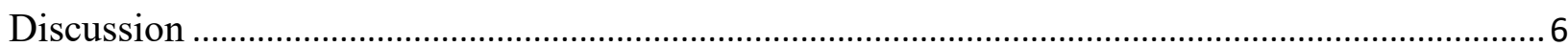

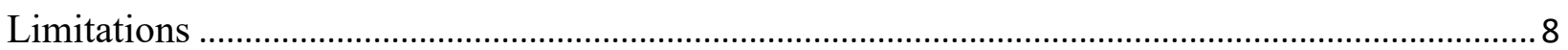

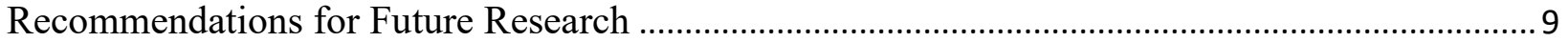

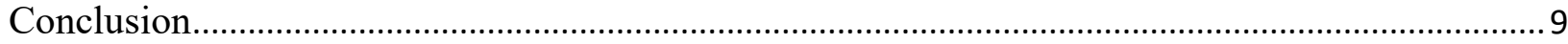

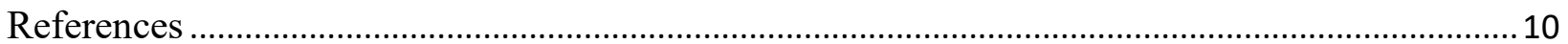




\section{LIST OF TABLES}

Table 1 Labeled vs Measured Nicotine Content in $0 \mathrm{mg} / \mathrm{ml}$ labeled samples............................. 4

Table 2 Labeled vs Measured Nicotine Levels in $18 \mathrm{mg} / \mathrm{ml}$ labeled samples............................. 5 
The Nicotine Content of a Sample of E-cigarette Liquid Manufactured in the United States

Use of electronic cigarettes (EC) has dramatically increased in the United States since 2010 with a forecasted growth of 37\% between 2014 and 2019 (Mintel Group Ltd, 2015).

Currently, about 9 million adults in the U.S. use EC on a regular basis. Among current users, EC are viewed as healthier than smoking, with $22 \%$ of EC users having recently switched from tobacco cigarettes according to the Centers for Disease and Control and Prevention (CDC) (Schoenborn \& Gindi, 2015). Unfortunately, there is insufficient data available to determine if the health risks of using EC are truly less than using tobacco cigarettes.

The consumable component to EC is a solution (e-liquid) which contains four major ingredients: vegetable glycerin, ethylene glycol, nicotine, and flavoring. These ingredients are mixed into solution by large manufacturers or at small, local retail shops and in turn sold to consumers via online websites or retail stores. These e-liquid solutions are potentially mixed by people with little to no formal training resulting in varying levels of accuracy and consistency.

Nicotine is an addictive and toxic substance with mild exposure producing adverse effects ranging from mucosal irritation and burning sensations to abdominal pain, nausea, vomiting and diarrhea (Mishra et al., 2015). Toxicity is relatively high with the LD50, the amount of an ingested substance that kills 50 percent of a test sample, estimated to be $50-60 \mathrm{mg}$ in adults (National Institute for Occupational Safety and Health, 1994). In children, the LD50 is estimated to be $10 \mathrm{mg}$. Severe poisonings can result in difficulty breathing, seizures, coma, and even death. Because nicotine is both addictive and toxic in relatively small doses, it is important that concentrations of nicotine be at safe levels and accurately labeled on e-liquid bottles. 
There is little research on e-liquid nicotine concentration from domestic manufacturers. However, limited research outside of the U.S. found wide inconsistencies between the labeled concentration of nicotine in e-liquids and the actual nicotine concentration of the product (Kim, Goniewicz, Yu, Kim, \& Gupta, 2015). Additional studies analyzing the toxicological profile of EC solutions found that nicotine levels in these products may reach unsafe levels (Hahn et al., 2014). This research suggests that EC may not be any safer than tobacco cigarettes, which is important for both consumers and health care providers.

Many healthcare providers are unaware of the differences between smoking tobacco cigarettes and EC use. Healthcare providers must be informed and able to share accurate information about possible health risks of ECs, including the risks inherent in a solution that is mixed without adequate safeguards to ensure accurate levels of nicotine in the e-liquid.

Inaccurately labeled low nicotine concentration in e-liquid may lead consumers to believe they can consume a larger amount of e-liquid without fear of overdosing on nicotine. However, due to possible varying levels of labeled nicotine from seller to seller, the next bottle purchased may have a higher amount and, once consumed at the usual rate, may cause unexpected adverse effects. An inaccurately high nicotine concentration may have an even greater impact on the consumer. Potentially lethal doses due to an accidental mixing mistake are possible given the availability of extremely concentrated nicotine $(>150 \mathrm{mg} / \mathrm{ml})$ in local mixing shops. Therefore, the purpose of this study is to compare the labeled nicotine amount on eliquids with their measured nicotine content.

\section{Background}

Electronic cigarettes are composed of a battery unit that heats a coil around a wick containing the e-liquid solution, which aerosolizes it into a dense, white vapor. This solution can be held in a 
tank or reservoir on top of the EC unit, or alternatively, it can be dripped directly onto the wick and coils.

E-liquid typically is available in nicotine concentrations of $0,3,6,12,18$, or $24 \mathrm{mg} / \mathrm{ml}$. It is available in a multitude of flavors. Vendors sell it online or locally. Some consumers also mix e-liquid solution themselves, using readily available ingredients or kits sold online.

\section{Methods}

The seven most popular online manufacturers or distributors of e-liquids were selected using a Google search along with Alexa page rankings and the key words: vape juice, $e$ juice, electronic cigarette, e-cig juice, and e-liquid. E-liquid samples of the five most popular flavors from each manufacturer or distributor were purchased in nicotine concentrations of 0 $\mathrm{mg} / \mathrm{ml}$ and $18 \mathrm{mg} / \mathrm{ml}$. Of the samples purchased $(\mathrm{n}=70)$, all were labeled as produced in the United States of America. The researchers anonymized the samples before sending them to an independent university lab for testing.

The nicotine content in the e-juices was measured by weighing an aliquot of e-juice $(2 \mu 1)$ in a vial, adding methanol $(1 \mathrm{ml})$ to it and weighing it again. These samples were then delivered to an independent lab which analyzed the samples using high performance liquid chromatography. The nicotine content in the e-juices was calculated by using a calibration curve established by standard nicotine samples. The nicotine content in the e-juices was calculated using the density of the e-juices, found by weighing $1.00 \mathrm{ml}$ of e-juice. The density of methanol $(0.792 \mathrm{~g} / \mathrm{ml})$ was used for the density of the sample. The nicotine detection limit was $0.01 \mathrm{mg} / \mathrm{ml}$ and quantification limit was $0.05 \mathrm{mg} / \mathrm{ml}$. 


\section{Results}

The e-juice data including the nicotine content labeled by the manufacturer and the measured nicotine concentrations are summarized in Tables 1 and 2.

In the 35 samples labeled $0 \mathrm{mg} / \mathrm{ml}$, nicotine was detected (trace: $>0.01 \mathrm{mg} / \mathrm{ml}$ ) in $91.4 \%$ of the samples (range $=0.01$ to $23.9 \mathrm{mg} / \mathrm{ml} ; \mathrm{M}=2.9 ; \mathrm{SD}=7.2$ ). Six samples from two manufacturers labeled as $0 \mathrm{mg} / \mathrm{ml}$ were found to contain nicotine in amounts ranging from 5.7 $\mathrm{mg} / \mathrm{ml}$ to $23.9 \mathrm{mg} / \mathrm{ml}$.

Table 1 Labeled vs Measured Nicotine Content in $0 \mathrm{mg} / \mathrm{ml}$ labeled samples

\begin{tabular}{lllll}
\hline Sample & & & $\begin{array}{l}\text { Labeled } \\
\text { Nicotine }\end{array}$ & $\begin{array}{l}\text { Measured } \\
\text { Nicotine } \\
\text { Number }\end{array}$ \\
\hline 1 & Manufacturer & Flavor & (mg/ml) & (mg/mL) \\
2 & Beard Vape Co. & Sweet Tooth & 0 & trace \\
3 & Cuttwood & \#05 & 0 & 0.00 \\
4 & Johnson Creek Vapor Co. & Red Oak Domestic & 0 & 0.00 \\
5 & Johnson Creek Vapor Co. & Red Oak Island & 0 & trace \\
6 & Johnson Creek Vapor Co. & Red Oak Solstice & 0 & trace \\
7 & Johnson Creek Vapor Co. & Red Oak Tennessee Cured & 0 & trace \\
8 & Johnson Creek Vapor Co. & Red Oak Vanda & 0 & trace \\
9 & Lizard Juice & 101 Highway & 0 & trace \\
10 & Lizard Juice & Dark Lizard & 0 & trace \\
11 & Lizard Juice & Heavens Cream & 0 & trace \\
12 & Lizard Juice & Lizard Milk & 0 & trace \\
13 & Lizard Juice & LJ4 & 0 & trace \\
14 & Lizard Juice & Outlaw & 0 & trace \\
15 & Mount Baker Vapor & Hawk Sauce & 0 & 21.32 \\
16 & Mount Baker Vapor & Cinnamon Roll & 0 & 22.05 \\
17 & Mount Baker Vapor & Moo Juice & 0 & 22.41 \\
18 & Mount Baker Vapor & Thug Juice & 0 & 23.91 \\
19 & Mount Baker Vapor & Extreme Ice & 0 & trace \\
20 & Time Bomb Vapors & TNT & trace \\
21 & vapewild.com & On Cloud Custard & (s+c)2 & 0.00 \\
22 & vapewild.com & & 0 & trace
\end{tabular}




\begin{tabular}{lllll}
23 & vapewild.com & Circus Bear & 0 & trace \\
24 & vapewild.com & Fruit Hoops & 0 & trace \\
25 & vapewild.com & Smurf Cake & 0 & trace \\
26 & VaporFi & Bahama Breeze & 0 & trace \\
27 & VaporFi & Blueberry Cheesecake & 0 & trace \\
28 & VaporFi & Juicy Fruit & 0 & trace \\
29 & VaporFi & Rocco's Pearadise & 0 & trace \\
30 & VaporFi & Tobaccolicious & 0 & trace \\
31 & Vista Vapors & Blue Raspberry & 0 & 5.67 \\
32 & Vista Vapors & American Tobacco & 0 & 8.11 \\
33 & Vista Vapors & Cotton Candy & 0 & trace \\
34 & Vista Vapors & Green Apple & 0 & trace \\
35 & Vista Vapors & Icy Menthol & 0 & trace \\
\hline
\end{tabular}

The 35 e-juices labeled $18 \mathrm{mg} / \mathrm{ml}$ nicotine were found to contain between 11.6 and 27.4 $\mathrm{mg} / \mathrm{ml}(\mathrm{M}=18.7 \mathrm{SD}=3.3)$ nicotine. The percent deviation ranged from $-35.6 \%$ to $52.2 \%$ $(\mathrm{M}=4.2 \% \mathrm{SD}=18.4)$ meaning that the e-juices labeled with $18 \mathrm{mg} / \mathrm{ml}$ nicotine had as little as $35 \%$ less nicotine and as much as 52\% more nicotine than labeled. Assuming a tolerance level of $\pm 10 \%, 13$ samples $(37 \%)$ were within this range and 22 samples $(63 \%)$ exceeded this range.

Table 2 Labeled vs Measured Nicotine Levels in $18 \mathrm{mg} / \mathrm{ml}$ labeled samples

\begin{tabular}{|c|c|c|c|c|c|}
\hline $\begin{array}{l}\text { Sample } \\
\text { Number }\end{array}$ & Manufacturer & Flavor & $\begin{array}{l}\text { Labeled } \\
\text { Nicotine } \\
(\mathrm{mg} / \mathrm{ml})\end{array}$ & $\begin{array}{l}\text { Measured } \\
\text { Nicotine } \\
(\mathrm{mg} / \mathrm{mL})\end{array}$ & $\begin{array}{l}\text { Nicotine } \\
\text { Deviation } \\
(\%)\end{array}$ \\
\hline 36 & Alpha Vape & Sweet Tooth & 18 & 11.64 & $-35.31 \%$ \\
\hline 37 & Beard Vape Co. & $\# 05$ & 18 & 17.70 & $-1.66 \%$ \\
\hline 38 & Cuttwood & Unicorn Milk & 18 & 20.67 & $14.85 \%$ \\
\hline 39 & Johnson Creek Vapor Co. & Red Oak Domestic & 18 & 18.32 & $1.78 \%$ \\
\hline 40 & Johnson Creek Vapor Co. & Red Oak Island & 18 & 18.78 & $4.36 \%$ \\
\hline 41 & Johnson Creek Vapor Co. & Red Oak Solstice & 18 & 20.98 & $16.57 \%$ \\
\hline 42 & Johnson Creek Vapor Co. & Red Oak Tennessee Cured & 18 & 21.01 & $16.74 \%$ \\
\hline 43 & Johnson Creek Vapor Co. & Red Oak Vanda & 18 & 23.45 & $30.29 \%$ \\
\hline 44 & Lizard Juice & Outlaw & 18 & 17.60 & $-2.24 \%$ \\
\hline 45 & Lizard Juice & LJ4 & 18 & 17.85 & $-0.86 \%$ \\
\hline 46 & Lizard Juice & Heavens Cream & 18 & 18.87 & $4.85 \%$ \\
\hline
\end{tabular}




\begin{tabular}{|c|c|c|c|c|c|}
\hline 47 & Lizard Juice & 101 Highway & 18 & 19.20 & $6.65 \%$ \\
\hline 48 & Lizard Juice & Lizard Milk & 18 & 21.84 & $21.35 \%$ \\
\hline 49 & Lizard Juice & Dark Lizard & 18 & 23.04 & $27.98 \%$ \\
\hline 50 & Mount Baker Vapor & Hawk Sauce & 18 & 18.09 & $0.52 \%$ \\
\hline 51 & Mount Baker Vapor & Thug Juice & 18 & 21.01 & $16.75 \%$ \\
\hline 52 & Mount Baker Vapor & Moo Juice & 18 & 22.43 & $24.59 \%$ \\
\hline 53 & Mount Baker Vapor & Cinnamon Roll & 18 & 22.74 & $26.31 \%$ \\
\hline 54 & Mount Baker Vapor & Extreme Ice & 18 & 27.43 & $52.37 \%$ \\
\hline 55 & Time Bomb Vapors & TNT & 18 & 14.68 & $-18.42 \%$ \\
\hline 56 & vapewild.com & Circus Bear & 18 & 13.98 & $-22.33 \%$ \\
\hline 57 & vapewild.com & On Cloud Custard & 18 & 14.70 & $-18.35 \%$ \\
\hline 58 & vapewild.com & $(s+c) 2$ & 18 & 14.86 & $-17.46 \%$ \\
\hline 59 & vapewild.com & Smurf Cake & 18 & 15.15 & $-15.86 \%$ \\
\hline 60 & vapewild.com & Fruit Hoops & 18 & 21.74 & $20.79 \%$ \\
\hline 61 & VaporFi & Juicy Fruit & 18 & 14.28 & $-20.68 \%$ \\
\hline 62 & VaporFi & Bahama Breeze & 18 & 15.12 & $-16.01 \%$ \\
\hline 63 & VaporFi & Blueberry Cheesecake & 18 & 18.85 & $4.72 \%$ \\
\hline 64 & VaporFi & Rocco's Pearadise & 18 & 19.36 & $7.53 \%$ \\
\hline 65 & VaporFi & Tobaccolicious & 18 & 19.99 & $11.08 \%$ \\
\hline 66 & Vista Vapors & Blue Raspberry & 18 & 15.46 & $-14.11 \%$ \\
\hline 67 & Vista Vapors & Cotton Candy & 18 & 17.84 & $-0.89 \%$ \\
\hline 68 & Vista Vapors & Green Apple & 18 & 18.06 & $0.32 \%$ \\
\hline 69 & Vista Vapors & Icy Menthol & 18 & 18.46 & $2.53 \%$ \\
\hline 70 & Vista Vapors & American Tobacco & 18 & 21.19 & $17.73 \%$ \\
\hline
\end{tabular}

\section{Discussion}

Electronic cigarettes and their components are a relatively new industry with an unknown potential for severe health consequences (Food and Drug Administration, 2013). In an attempt to self-regulate, a volunteer organization of e-liquid manufactures created the American E-Liquid Manufacturing Standards Association (AEMSA) with the purpose of "creating responsible and sustainable standards for the safe manufacturing of e-liquids" (AEMSA, 2015, p. 3). Among the several standards that AEMSA promotes is accuracy of nicotine content in e-liquid products. This includes confirming the accuracy of nicotine content of base mix products from suppliers 
prior to the creation of the final e-liquid product, certification standards for measuring equipment, maximum allowable nicotine content of $36 \mathrm{mg} / \mathrm{ml}$ in the final product, and a tolerance level within $\pm 10 \%$ of labeled nicotine content. Members are held accountable to these standards and will lose their certification if found out of compliance. While the effort to selfregulate is laudable, most manufactures find little incentive to join AEMSA at this time. None of the most popular brands or samples tested in this study were produced from AEMSA certified manufacturers.

This study identified that nicotine levels of e-liquids varied considerably from the labeled amount. In the samples labeled $18 \mathrm{mg} / \mathrm{ml}$, only $37 \%$ were within the AEMSA recommended $\pm 10 \%$ of the labeled nicotine content. More concerning, nearly a quarter (23.6\%) of tested samples exceeded the AEMSA recommended range by greater than $20 \%$. These findings were similar to results of other studies conducted in several countries (Cheng, 2014; Davis, Dang, Kim, \& Talbot, 2015; Farsalinos et al., 2015; Goniewicz, Hajek, \& McRobbie, 2013; Hahn et al., 2014; Kim et al., 2015)

One important finding in this study is the presence of nicotine in samples labeled as 0 $\mathrm{mg} / \mathrm{ml}$ nicotine. This study found that nearly every sample labeled $0 \mathrm{mg} / \mathrm{ml}(91.4 \%)$ had detectable trace amounts $(>0.01 \mathrm{mg} / \mathrm{ml})$ of nicotine. Trace levels of nicotine in samples reported to have $0 \mathrm{mg} / \mathrm{ml}$ are dangerous to consumers with allergies to the substance. Nicotine, even in small doses has potent addictive side effects (Mishra et al., 2015). Consumers who think they are using a product free from nicotine are instead being exposed to nicotine, creating a potential for addiction. Surprisingly, several $0 \mathrm{mg} / \mathrm{ml}$ samples were found to have levels of nicotine higher than many of the samples labeled with $18 \mathrm{mg} / \mathrm{ml}$. Four out of five samples labeled $0 \mathrm{mg} / \mathrm{ml}$ nicotine from Mount Baker Vapor were nearly identical to their nicotine-containing counterparts 
with an average $22.4 \mathrm{mg} / \mathrm{ml}$ content (samples 15-18). Vista Vapors also had two samples labeled $0 \mathrm{mg} / \mathrm{ml}$ nicotine which were measured to contain $5.67 \mathrm{mg} / \mathrm{ml}$ and $8.11 \mathrm{mg} / \mathrm{ml}$ each (samples 31 , 32). The cause of these discrepancies could be related to cross-contamination, mislabeling or simply mishandling of the measuring and mixing process; however, given the toxicity of nicotine, this presents a clear and present danger to the consumer. Due to the inaccurate labeling of e-liquids and the potential for severe health risks for the consumer, regulation of EC is recommended.

On August 8, 2016, the Food and Drug Administration (FDA) introduced regulation deemed EC and their components, including e-liquid, as tobacco products (2016). As part of the new rules, e-liquid manufacturers will be required to register with the FDA and apply for a license to produce each flavor and nicotine concentration of their e-liquids. This process will require the listing of each ingredient along with its quantity and health effects. Failure to follow these regulations, including the accurate reporting and labeling of nicotine concentrations in eliquid solutions could result in significant fines and penalties. These regulations are similar to laws several other countries have enacted in order to protect the consumers of EC and its e-liquid refill solutions. The findings of this study support the need for federal regulation of e-cigarettes.

\section{Limitations}

While this study compared the labeled vs measured nicotine in e-liquids, there are some limitations. There are many other chemicals in e-liquids that may affect consumer's health that this study did not analyze. Additionally, a random sample of manufacturers in the U.S. were studied. The sample size was small $(n=70)$, but larger than previous studies done outside the U.S. (Kim, et al., 2015). This study also did not measure e-liquids mixed in small retail shops or by the consumers themselves. 


\section{Recommendations for Future Research}

Future research is needed on the labeled vs measured nicotine levels in retail stores selling and mixing e-liquids locally. Research addressing other chemicals used to flavor e-liquids also needs to be conducted. In addition, health care provider and consumer perceptions of nicotine content in e-liquids needs to be explored. Finally, long term studies on the health consequences of e-cigarette use is needed, similar to previous research on traditional tobacco products.

\section{Conclusion}

This study demonstrated there is a disparity between the labeled and measured content of nicotine in e-liquids in the U.S. These findings support the recent regulation changes enacted by the FDA to require manufacturers to comply with standards to ensure accuracy of labeling. Additional routine testing of nicotine concentrations should be conducted to evaluate the effectiveness of these regulations on future e-liquid production. Practitioners need to be aware patients who report e-cigarette use may be consuming nicotine in uncertain quantities with potentially serious adverse health effects. 


\section{References}

AEMSA. (2015). E-Liquid Manufacturing Standards. Retrieved from http://www.aemsa.org/wpcontent/uploads/2012/10/2015-AEMSA-Standards_Version-2-2-5.20.15.pdf

Cheng, T. (2014). Chemical evaluation of electronic cigarettes. Tobacco Control, 23(Suppl 2), ii11-ii17. doi:10.1136/tobaccocontrol-2013-051482

Davis, B., Dang, M., Kim, J., \& Talbot, P. (2015). Nicotine Concentrations in Electronic Cigarette Refill and Do-It-Yourself Fluids. Nicotine \& Tobacco Research, 17(2), 134141. doi:10.1093/ntr/ntu080

Farsalinos, K. E., Gillman, I. G., Melvin, M. S., Paolantonio, A. R., Gardow, W. J., Humphries, K. E., .. . Voudris, V. (2015). Nicotine Levels and Presence of Selected TobaccoDerived Toxins in Tobacco Flavoured Electronic Cigarette Refill Liquids. International Journal Of Environmental Research And Public Health, 12(4), 3439-3452. doi:10.3390/ijerph120403439

Food and Drug Administration. (2013). FDA Warns of Health Risks Posed by E-Cigarettes. Retrieved from http://www.fda.gov/ForConsumers/ConsumerUpdates/ucm173401.htm Food and Drug Administration. (2016). Deeming tobacco products to be subject to the federal food, drug, and cosmetic act, as amended by the family smoking prevention and tobacco control act; restrictions on the sale and distribution of tobacco products and required warning statements for tobacco products. Federal Register: The Daily Journal of the United States, 81 Fed. Reg.(90), 28973-29106.

Goniewicz, M. L., Hajek, P., \& McRobbie, H. (2013). Nicotine content of electronic cigarettes, its release in vapour and its consistency across batches: regulatory implications. Addiction, 109(3), 500-507. doi:10.1111/add.12410 
Hahn, J., Monakhova, Y. B., Hengen, J., Kohl-Himmelseher, M., Schüssler, J., Hahn, H., . . Lachenmeier, D. W. (2014). Electronic cigarettes: overview of chemical composition and exposure estimation. Tobacco Induced Diseases, 12(1), 23-23. doi:10.1186/s12971-0140023-6

Kim, S., Goniewicz, M. L., Yu, S., Kim, B., \& Gupta, R. (2015). Variations in label information and nicotine levels in electronic cigarette refill liquids in South Korea: regulation challenges. International Journal Of Environmental Research And Public Health, 12(5), 4859-4868. doi:10.3390/ijerph120504859

Mintel Group Ltd. (2015). Smoking cessation and e-cigarettes - US - March 2015. Retrieved from http://www.mintel.com/

Mishra, A., Chaturvedi, P., Datta, S., Sinukumar, S., Joshi, P., \& Garg, A. (2015). Harmful effects of nicotine. Indian Journal of Medical and Paediatric Oncology : Official Journal of Indian Society of Medical \& Paediatric Oncology, 36(1), 24-31. doi:10.4103/09715851.151771

National Institute for Occupational Safety and Health (NIOSH). (1994). Nicotine. Retrieved from http://www.cdc.gov/niosh/idlh/54115.html

Schoenborn, C. A., \& Gindi, R. M. (2015). Electronic cigarette use among adults: United States, 2014. Hyattsville, MD: National Center for Health Statistics. Retrieved from http://www.cdc.gov/nchs/data/databriefs/db217.pdf. 